\title{
Predicting PANCE Outcomes from First Year Evaluative Measures in a PBL Curriculum
}

Anthony Goreczny

Chatham University, goreczny@chatham.edu

Susan Hawkins

Chatham University, hawkins@chatham.edu

John R. Laird

Chatham University, laird@chatham.edu

Follow this and additional works at: https://nsuworks.nova.edu/ijahsp

Part of the Medical Education Commons, and the Other Medicine and Health Sciences Commons

\section{Recommended Citation}

Goreczny A, Hawkins S, Laird JR. Predicting PANCE Outcomes from First Year Evaluative Measures in a PBL Curriculum. The Internet Journal of Allied Health Sciences and Practice. 2020 Jan 01;18(3), Article 7.

This Manuscript is brought to you for free and open access by the College of Health Care Sciences at NSUWorks. It has been accepted for inclusion in Internet Journal of Allied Health Sciences and Practice by an authorized editor of NSUWorks. For more information, please contact nsuworks@nova.edu. 


\title{
Predicting PANCE Outcomes from First Year Evaluative Measures in a PBL Curriculum
}

\begin{abstract}
Purpose: Previous research has explored various Physician Assistant (PA) student evaluative measures to see if they have predictive validity with regard to Physician Assistant National Certifying Exam (PANCE) scores. Recent literature has begun to evaluate how measures from the first year of didactic education might be helpful in identifying at-risk individuals early in the program. The purpose of this paper was to extend work in that area within a problem-based learning (PBL) curriculum. Method: Participants included 140 students from two consecutive PA classes. Data were imported regarding each student's evaluative measures of multiple choice question (MCQ) examinations, patient management assessments (PMA), a form of modified essay question (MEQ) examination, and facilitator evaluation ratings (FERs) from the end of each of six curricular units that comprise the didactic year. Results: Correlational analyses revealed all MCQ and MEQ (PMA) scores correlated significantly with PANCE scores. Regression analyses revealed that scores from two specific MCQ unit exams and one specific MEQ unit exam produced a three-factor model that accounted for $57 \%$ of variance in PANCE scores. FERs, though significantly correlated with PANCE scores, did not add to the predictive power. Conclusions: Use of MCQ and MEQ scores from the first year of didactic training in PA programs can successfully predict PANCE scores and may therefore be helpful in identifying students who are at risk for poor PANCE performance on their first attempt. Having such information available can direct faculty to students who need extra help early in their educational programs to increase likelihood of their success. With the significant correlations between FERs and PANCE scores, it is clear that faculty who facilitate PBL are also able to identify students who might be at risk based on their interactions during PBL sessions and can also utilize this information to assist student
\end{abstract}

\section{Author Bio(s)}

Anthony J. Goreczny, PhD, is a Professor in the School of Health Sciences at Chatham University in Pittsburgh, PA. He is also a licensed psychologist in the state of Pennsylvania.

Susan Hawkins, MSEd., PA-C. is a Professor in the School of Health Sciences at Chatham University in Pittsburgh, PA. She is also a licensed physician assistant in the state of Pennsylvania.

John Laird, ND, is an Associate Professor in the School of Health Sciences at Chatham University in Pittsburgh, PA. He is also a naturopathic physician. 


\title{
IIIAHSP \\ The Internet Joumal of Allied Health Sciences and Practice \\ Dedicated to allied health professional practice and education
}

Vol. 18 No. 3 ISSN 1540-580X

\section{Predicting PANCE Outcomes from First Year Evaluative Measures in a Problem-Based Learning Curriculum}

\author{
Anthony Goreczny \\ Susan Hawkins \\ John R. Laird \\ Chatham University \\ United States
}

\begin{abstract}
Purpose: Previous research has explored various Physician Assistant (PA) student evaluative measures to see if they have predictive validity with regard to Physician Assistant National Certifying Exam (PANCE) scores. Recent literature has begun to evaluate how measures from the first year of didactic education might be helpful in identifying at-risk individuals early in the program. The purpose of this paper was to extend work in that area within a problem-based learning (PBL) curriculum. Method: Participants included 140 students from two consecutive PA classes. Data were imported regarding each student's evaluative measures of multiple choice question (MCQ) examinations, patient management assessments (PMA), a form of modified essay question (MEQ) examination, and facilitator evaluation ratings (FERs) from the end of each of six curricular units that comprise the didactic year. Results: Correlational analyses revealed all MCQ and MEQ (PMA) scores correlated significantly with PANCE scores. Regression analyses revealed that scores from two specific MCQ unit exams and one specific MEQ unit exam produced a three-factor model that accounted for $57 \%$ of variance in PANCE scores. FERs, though significantly correlated with PANCE scores, did not add to the predictive power. Conclusions: Use of MCQ and MEQ scores from the first year of didactic training in PA programs can successfully predict PANCE scores and may therefore be helpful in identifying students who are at risk for poor PANCE performance on their first attempt. Having such information available can direct faculty to students who need extra help early in their educational programs to increase likelihood of their success. With the significant correlations between FERs and PANCE scores, it is clear that faculty who facilitate PBL are also able to identify students who might be at risk based on their interactions during PBL sessions and can also utilize this information to assist student
\end{abstract}

Keywords: problem-based learning, PBL, PANCE, curriculum, outcomes curriculum, prediction, andragogy, examinations, evaluations 


\section{INTRODUCTION}

Problem-based learning (PBL) is an andragogy, a method of facilitating adult learning, that utilizes self-directed and collaborative learning in a small group context. One of the tenets of andragogy is that as people mature, their approach to learning becomes decreasingly topic-focused and increasingly problem-focused. ${ }^{1} \mathrm{PBL}$ has been incorporated in physician assistant (PA) programs to various degrees, for example, entirely PBL-based programs; hybrid models that are PBL-centered with complementary lecture-based courses; and lecture-based programs that utilize the PBL process in some courses. The intent of PBL in a PA program is to foster medical knowledge acquisition and clinical reasoning in an environment that simulates medical practice. ${ }^{2}$ Students are encouraged to utilize and build upon previous knowledge through a process of questioning and metacognition that identifies the limits of their knowledge. The role of instructors is to be facilitators who challenge students to identify the limits of their knowledge, guide students in acquisition of new medical knowledge and appropriate clinical reasoning, and promote an environment in which all students feel safe to explore what they don't know, share what they know, and question each other. ${ }^{3}$ Facilitators do not provide information. A PBLcentered curriculum is a complex and dynamic process concerned with molding student clinical behavior as well as promoting medical knowledge acquisition in the didactic portion of a PA program.

A key challenge of student assessment in a PBL-centered curriculum is to assess both traditional medical knowledge and simulated clinical reasoning. This has been accomplished by administering multiple choice exams (MCQ) and patient management assessments (PMA) in a modified essay question (MEQ) format along with structured facilitator evaluations of student PBL performance. MCQ exams primarily assess medical knowledge, and MEQ exams assess clinical reasoning along with medical content. Facilitator evaluation ratings (FER) assess processes involving medical knowledge as well as behaviors in small groups. Comparisons between PBL and lecture-based curricula in medical schools and PA programs have demonstrated that PBL is equivalent to lecture in knowledge acquisition. For example, a PA program with dual PBL and lecture-based tracks found that students performed equally well in organ system and skills subsets, with PBL-based students performing better than lecture-based students in applying scientific concepts and lecture-based students performing better than PBL-based students in clinical therapeutics. ${ }^{4} \mathrm{~A}$ systematic review comparing student learning outcomes on basic medical science examinations and problem solving skills found that hybrid PBL students performed significantly better than traditional teaching (lecture) students in $75 \%$ and $80 \%$ of the studies respectively. ${ }^{5}$

PA programs have utilized MCQ, MEQ, and practical exams as formative tools to assess student competency within a program and as markers of progress toward readiness for success on the Physician Assistant National Certifying Exam (PANCE). PA programs have examined whether their assessment methods predict student outcomes on the PANCE. As one such example, a hybrid PBL program found that a combination of a summative exam at the end of the clinical year and the mean score on the didactic year MCQ exams were most predictive of identifying at-risk students (i.e., students who scored less than or equal to 375 on the PANCE). ${ }^{6}$ Selfdeveloped standardized exams that simulate the PANCE exam are used by some PA programs as a summative assessment of students. A study of five lecture-based PA programs found that a combined score on two summative exams and the Physician Assistant Clinical Knowledge Rating and Assessment Tool (PACKRAT) administered in the clinical year had the strongest correlation with student PANCE scores. ${ }^{7}$ The Physician Assistant Education Association (PAEA) developed standardized end of rotation specialty exams for students in their second-year clinical rotations. A retrospective study of three lecture-based PA programs found that a composite score on seven PAEA end of rotation exams had a strong correlation with the PANCE, which suggests that end of rotation exams could replace a large summative exam as a measure of student readiness for the PANCE. ${ }^{8}$

PBL programs have utilized facilitator evaluations to assess student knowledge acquisition and integration, clinical reasoning, selfdirected learning, communication, and teamwork skills. The degree to which facilitator evaluations correlate with student performance on written or MCQ exams is important to ascertain because formative evaluations serve to mold student learning and behavior. A sixyear retrospective study of students in the hybrid PBL program at Penn State University School of Medicine investigated the relationship between facilitator scores for student knowledge and their written exam grades. It found that facilitators' scores accounted for a mean variance of only $14.5 \%$ on exam grades. This was largely a result of significant facilitator overestimation of student performance among those who were in the bottom quartile of the class. ${ }^{9}$ Participation is an important component of PBL sessions because it serves to demonstrate students' knowledge acquisition and clinical reasoning. A study of first and second year students at the Indiana University School of Dentistry attempted to determine whether a student's level of group participation related to their biomedical knowledge as measured by two faculty-developed questions of biomedical content derived from the group's learning issues. It found a significant relationship between first year students' level of participation and success in answering one factual recall question. Relationships between group participation and scores on an applied problem by first year students as well as factual and applied questions by second year students were non-significant.

The lack of relationship was hypothesized to be a result of students primarily studying the faculty-defined PBL learning objectives rather than going through the process of self-directed learning, an integral part of PBL. ${ }^{10}$ Assessment of knowledge via a two question "quiz" may not be adequate and could be considered a weakness of that study. 
Given costs associated with attending graduate school and efforts to help students succeed, PA programs have attempted to identify early predictors for success on the PANCE with the objective of identifying at-risk students who might benefit from early academic and behavioral intervention. To that end, one lecture-based PA program found a strong correlation between PANCE scores and student grades in a first-year pharmacology course as well as a moderate correlation between PANCE scores and first-year anatomy course grades. There was also a strong correlation between a student's overall grade point average (GPA) and PANCE pass/fail status. ${ }^{11} \mathrm{~A}$ retrospective study of students in the lecture-based PA program at the University of Kentucky determined that the average GPA across three foundational first-year courses, anatomy, physiology and pharmacology, had the strongest correlation with PANCE performance. ${ }^{12}$ While there has been some minimal success predicting PANCE scores from first-year academic indicators, all of the data reviewed have relied solely on course grades, which tend to focus on science-based courses as opposed to clinically-focused evaluations.

The purpose of the current study was to build on the 2011 Ennulat article, which found MCQ exams given in the first year to be predictive of PANCE scores. ${ }^{6}$ The current study replicated the Ennulat research design evaluating predictive ability of MCQ exams and extended that work by including additional assessments of Patient Management Assessment (an MEQ exam) and Facilitator Evaluation Ratings. The reason for this addition was to identify whether first-year program assessments that focus directly on clinical reasoning in addition to MCQ exams are predictive of PANCE performance. Having multiple markers as guideposts for student performance in the first didactic year may help identify at-risk students who can benefit from remedial work and advisor-specific intervention, thus reducing student attrition and fostering improved performance on the PANCE. In addition, the Ennulat article showed the average of MCQ scores during the didactic year has predictive significance. In this study, we sought to determine (a) which of the individual MCQ test scores were predictive of PANCE scores and (b) if any other first year test scores or facilitator ratings would also correlate with and help predict PANCE scores.

\section{METHOD}

Students from two consecutive classes of a 2-year master's degree physician assistant (PA) program were the 140 subjects for this study. Inclusion criteria were all students in these 2 classes (Class of 2016 and Class of 2017). Exclusion criteria were students who had matriculated into the program in a previous year and were returning following leave of absence or course failure. These students were excluded because each had previous experience with a portion of the curricular material and evaluations; thus, they were not comparable to students experiencing the materials for the first time. Approval for this study was granted by the University's Institutional Review Board.

Data collected for each student consisted of evaluative measures that were already available to one of the authors as a key faculty member and course director. The PA program's first year PBL clinical medicine course consists of six consecutive five-week units (three units per semester) organized by organ system. Groups of 7 to 9 students each are assigned to a different facilitator for each unit such that each student experiences six different facilitators over the 2 semesters. The following evaluative measures are administered at the end of each of six units: 1) multiple choice examinations (MCQ 1-6); 2) patient management assessments (PMA 1-6); and 3) end-of-unit facilitator evaluation ratings (FER 1-6). Results of these evaluative measures as well as results from the Physician Assistant National Certifying Examination (PANCE) administered after PA program completion were collected.

The MCQ exams consist of 100 questions related to any of the medical topics covered in the corresponding unit. These are designed to be similar in appearance and content to the PANCE exams. The PMA exams are administered in Modified Essay Question (MEQ) format and contain three cases each. Students are given the presenting problems and proceed (one quiz at a time) to choose a differential diagnosis, ask questions of the patient, request portions of the physical examination, choose diagnostic tests and write a treatment plan, requiring rationales for each selection. More information is given after each quiz is submitted, thereby allowing students to proceed in a manner that can indicate the clinical thinking process. Exams are scored by faculty members using a key which contains required items, allowable items, and incorrect items. A total score is computed consisting of the total number of errors made. Thus, for this assessment, a higher score indicates more errors and therefore worse performance.

Each PBL facilitator completed an evaluation form (FER) for each student in their group at the end of the unit. Students were evaluated with a 4-point Likert scale in seven domain areas: Clinical Reasoning (CR), Knowledge Integration (KI); Self-Directed Learning (SDL), Participation (PAR), Team Skills (TS), Evaluation (EVAL), and Communication (COM). The first three areas (CR, KI, SDL) are largely processes involving medical knowledge; the other four areas (PAR, TS, EVAL, and COM) involve small group behaviors. Although reliability and validity of this particular instrument have not been assessed, the domain areas being evaluated originate from the recommendations of the Southern Illinois University model of PBL.

(c) The Internet Journal of Allied health Sciences and Practice, 2020 
The seminal publication of this method suggests assessment in the following areas that correspond to the domain areas in the FER: "clinical reasoning skills that are effective, and efficient," "the acquisition of an extensive knowledge base that is integrated from multiple disciplines," "self-directed learning skills," "ability to work effectively in a team setting," "accepting and giving constructive feedback," and "effective skills in ...communication and interpersonal skills." Although participation is not specifically mentioned, all the domain areas require student participation for the facilitator to successfully assess the student. ${ }^{2}$ Operational definitions, as well as the scoring rubric, can be found on the evaluation form (See Figure 1 in Appendix). Scores for each area, as well as total score for each FER, were computed.

Subjects were assigned a number, and all data were entered into a database based on the assigned number. The scores on all of these assessments were de-identified prior to data analysis. Data were entered into Microsoft Excel before migrating them into SPSS 18 software. No identifying information such as demographics was collected because the largely young female Caucasian sample would make students potentially identifiable. SPSS was used for all data analyses, including correlations and stepwise regression analyses.

\section{RESULTS}

The first step was to compute FER summative scores. Summative scores were computed across each evaluation period (i.e., FER1 is the summation of the ratings on each of the items on the FER Group Evaluation Form completed by the facilitator after the end of the first unit) and across each domain (i.e., FERCR is the summation of all of the facilitator ratings on clinical reasoning across all six evaluation periods). Descriptive statistics for all variables appear in Table 1.

Table 1: Descriptive Statistics for all Variables

\begin{tabular}{|c|c|c|c|c|c|}
\hline Variable & $\mathbf{n}$ & Mean & Standard Deviation & Minimum & Maximum \\
\hline PANCE & 129 & 504.13 & 86.00 & 331 & 759.0 \\
\hline MCQ1 & 140 & 70.61 & 8.10 & 44 & 90.0 \\
\hline MCQ2 & 140 & 70.99 & 8.43 & 42 & 87.8 \\
\hline MCQ3 & 135 & 71.13 & 8.91 & 45 & 90.0 \\
\hline MCQ4 & 131 & 73.77 & 8.16 & 50 & 91.2 \\
\hline MCQ5 & 131 & 75.41 & 7.41 & 58 & 91.0 \\
\hline MCQ6 & 131 & 75.01 & 8.03 & 54 & 91.2 \\
\hline PMA1 & 135 & 54.03 & 13.88 & 27 & 100.0 \\
\hline PMA2 & 135 & 52.50 & 10.81 & 28 & 91.0 \\
\hline PMA3 & 134 & 48.88 & 13.17 & 23 & 97.0 \\
\hline PMA4 & 131 & 52.34 & 10.30 & 26 & 84.0 \\
\hline PMA5 & 131 & 45.82 & 9.92 & 25 & 74.0 \\
\hline PMA6 & 131 & 44.99 & 11.16 & 22 & 82.0 \\
\hline FER1 & 132 & 20.11 & 2.74 & 12 & 26.0 \\
\hline FER2 & 130 & 21.04 & 2.74 & 12 & 26.0 \\
\hline FER3 & 115 & 22.20 & 2.13 & 15 & 26.0 \\
\hline FER4 & 121 & 22.23 & 2.10 & 16 & 26.0 \\
\hline FER5 & 117 & 22.35 & 2.10 & 15 & 28.0 \\
\hline FER6 & 121 & 23.43 & 2.02 & 17 & 28.0 \\
\hline FERCR & 85 & 18.44 & 2.03 & 13 & 23.0 \\
\hline FERKI & 85 & 19.03 & 2.31 & 14 & 24.0 \\
\hline FERSDL & 86 & 19.29 & 1.82 & 15 & 24.0 \\
\hline FERPAR & 85 & 17.69 & 2.07 & 11 & 24.0 \\
\hline FERTS & 85 & 19.55 & 1.51 & 17 & 22.0 \\
\hline FEREVAL & 86 & 18.88 & 1.70 & 14 & 22.0 \\
\hline FERCOM & 85 & 18.58 & 1.75 & 15 & 23.0 \\
\hline
\end{tabular}

Abbreviations: MCQ1 through MCQ6 - multiple choice exams 1 through 6, respectively; PMA1 through PMA6 - patient management assessments 1 through 6 respectively; FER1 through FER6 - total of ratings of students by FER facilitators at the end of units 1 through 6, respectively; FERCR average ratings of facilitators on clinical reasoning; FER-KI - average rating of facilitators on knowledge integration; FERSDL - average rating of facilitators on self-directed learning; FERPAR - average rating of facilitators on participation FERTS - average rating of facilitators on team skills; FEREVAL - average rating of facilitators on evaluation process; FERCOM - average rating of facilitators on communication skills

Upon completing computation of the summative scores, we then ran correlations between PANCE scores and all of the scores and ratings from the first year of study, including MCQ and PMA scores from each of the six test administrations and all of the summative FER scores (both the total score by unit and the average score by rating area, e.g., clinical reasoning, across the six units). As is clear 
from Table 2, all of the MCQ and PMA tests correlated significantly with PANCE scores. All the correlations were in the expected direction, with positive correlations between PANCE and MCQ scores and negative correlations between PANCE and PMA scores (as high PMA scores equal poor PMA performance). Also, all the FER total scores for each unit except for the first unit scores were statistically significant. Finally, of the FER summative scores across domains, only three (Clinical Reasoning, Knowledge Integration, and Self-Directed Learning) were statistically significant, and these are the three domain areas that seem most relevant.

Table 2: Correlations between PANCE test scores and predictor variables of MCQ test scores, PMA test scores, and FER facilitator ratings

\begin{tabular}{|c|c|c|c|}
\hline Predictor Variable & $\mathbf{r}$ & $\mathbf{p}$ & $\mathbf{n}$ \\
\hline MCQ1 & .526 & .000 & 129 \\
\hline MCQ2 & .517 & .000 & 129 \\
\hline MCQ3 & .590 & .000 & 129 \\
\hline MCQ4 & .556 & .000 & 129 \\
\hline MCQ5 & .608 & .000 & 129 \\
\hline MCQ6 & .678 & .000 & 129 \\
\hline PMA1 & -.299 & .001 & 129 \\
\hline PMA2 & -.431 & .000 & 129 \\
\hline PMA3 & -.476 & .000 & 129 \\
\hline PMA4 & -.485 & .000 & 129 \\
\hline PMA5 & -.314 & .000 & 129 \\
\hline PMA6 & -.469 & .000 & 129 \\
\hline FER1 & .054 & .557 & 122 \\
\hline FER2 & .292 & .001 & 120 \\
\hline FER3 & .346 & .000 & 111 \\
\hline FER4 & .261 & .004 & 119 \\
\hline FER5 & .311 & .001 & 116 \\
\hline FER6 & .228 & .013 & 119 \\
\hline FERCR & .311 & .004 & 85 \\
\hline FERKI & .447 & .000 & 84 \\
\hline FERSDL & .263 & .016 & 84 \\
\hline FERPAR & .136 & .214 & 85 \\
\hline FERRTS & .122 & .271 & 84 \\
\hline FEREVAL & .034 & .758 & 85 \\
\hline FERCOM & .174 & .113 & 84 \\
\hline
\end{tabular}

Abbreviations: MCQ1 through MCQ6 - multiple choice exams 1 through 6, respectively; PMA1 through PMA6 - patient management assessments 1 through 6 respectively; FER1 through FER6 - total of ratings of students by facilitators at the end of units 1 through 6, respectively; FERCR - average ratings of facilitators on clinical reasoning; FER-KI - average rating of facilitators on knowledge integration; FERSDL - average rating of facilitators on self-directed learning; FERPAR - average rating of facilitators on participation FERTS - average rating of facilitators on team skills; FEREVAL average rating of facilitators on evaluation process; FERCOM - average rating of facilitators on communication skills

In order to determine which of the first-year test scores and facilitator ratings most predicted PANCE scores, stepwise regression analyses were computed with PANCE scores as the dependent (criterion) variable. Three separate stepwise regression analyses were computed. With previous research showing that $M C Q$ scores have predictive ability with regards to the PANCE, MCQ test scores were used as independent variables in each of the analyses. ${ }^{6}$ The two MCQ scores that were most predictive of PANCE scores were MCQ 6 (hematology plus a review of all of the preceding organ systems) and MCQ 3 (cardiopulmonary). The first of the three analyses also included PMA scores as independent variables, with the second and third analyses including FER summative scores for each unit and FER summative scores for each domain area (respectively for the second and third analyses) as independent variables. Only those FER scores that correlated significantly with PANCE scores were included in these regression analyses. Only the first stepwise regression model revealed any variable other than MCQ score to add predictive value. That other value was the PMA 4 (gastrointestinal, genitourinary and renal) test score. Together, the three test scores of MCQ 6, MCQ 3, and PMA 4 predicted 57\% of the variance in PANCE scores. See Table 3 for summary statistics for this model. 
Table 3. Summary of Stepwise Regression Analysis and Beta Coefficients for Prediction of PANCE Scores

\begin{tabular}{|c|c|c|c|c|c|c|c|c|c|c|}
\hline \multicolumn{7}{|c|}{ Stepwise Model Statistics } & \multicolumn{3}{c|}{ Final 3-Variable Model Statistics } \\
Model & $R$ & $R^{2}$ & $R^{2}$ & $F$ & $d f$ & $p$ & $\begin{array}{c}\text { Unstandardized } \\
\text { Beta }\end{array}$ & $\begin{array}{c}\text { Standardized } \\
\text { Beta }\end{array}$ & $t$ & $p$ \\
\hline 1-MCG6 & .69 & .47 & .47 & 71.26 & 1 & .00 & 5.11 & .48 & 5.25 & .00 \\
\hline 2-MCQ3 & .73 & .54 & .06 & 44.74 & 2 & .00 & 2.57 & .25 & 2.71 & .01 \\
\hline 3-PMA4 & .75 & .57 & .03 & 33.45 & 3 & .00 & -1.75 & -.20 & -2.34 & 0.2 \\
\hline
\end{tabular}

\section{DISCUSSION}

Being able to identify academically at-risk students early in a PA program is important for making interventions that can improve academic performance, reduce attrition, and improve outcomes on the PANCE. Results from the current study revealed this may indeed be possible. Previous research has found strong correlations between second year standardized or summative exams and the PANCE. Although helpful, this approach does not identify at risk students until they have completed their first academic year when the bulk of medical content is learned. Faculty at some programs have begun to identify predictors of student success from first year information. For example, some PA programs have found that GPA in first year basic science courses or average first year overall GPA were positively correlated with PANCE scores. ${ }^{11,12}$ Also, a hybrid PBL program found that the average MCQ score over two semesters of a PBL course in clinical medicine was predictive of at risk students. ${ }^{6}$ In these circumstances, most if not all of the first year courses would have been completed by the time at risk students were identified, precluding effective remediation in the first year.

Given the varied degree to which programs incorporate PBL into the curriculum (e.g., lecture-based programs that use some PBL in courses versus PBL-focused didactic curricular experiences), it is essential to discern predictors of success in both types. A PBLcentered curriculum meshes learning the content of medicine along with learning clinical reasoning. In a PBL-centered curriculum, most of the medical content and clinical reasoning is learned in a self-directed format that comprises the majority of first year credits. Therefore, it is reasonable to compare student performance in the PBL course with PANCE scores rather than comparing basic science grades with the PANCE. This study identified three formative exams, two MCQ exams, and one MEQ exam (i.e., PMA) in the first year PBL course that have a positive correlation and predictive validity with PANCE scores. One MCQ exam occurs in the first semester. Therefore, at the end of the first semester it is possible to identify students who are at risk for poor performance on the PANCE. This allows faculty to recommend academic interventions such as individual tutoring, remediation, and meetings with the course instructor to correct and support student learning behaviors in the middle of the first year.

The three exams (MCQ3, PMA4, and MCQ6), which in concert are predictive of PANCE scores, encompass knowledge base and disorders that comprise a large portion of the PANCE. MCQ3 is cardiopulmonary; PMA4 is gastrointestinal, genitourinary, and renal; and MCQ6 is hematology plus a review of all the organ systems. This may account for the ability of these three exams to predict PANCE scores. There was a trend, especially among MCQ scores, for increasingly strong predictive ability (i.e., correlations with PANCE scores) as students progressed through the curriculum. This may reflect a learning curve on the part of students adapting to $\mathrm{PBL}$ and the nature of the evaluations that accompany it. Many students have not experienced MEQ exams, having gone through undergraduate programs that largely utilize MCQ exams and single-topic essays. They may not have experienced MCQ exams where the breadth of material covered is as large as that in a whole-unit exam model.

Previous research has investigated the ability of PBL facilitators to predict student academic performance based on facilitators' evaluations of students. ${ }^{9,10}$ Those studies revealed that facilitators' evaluations did not contribute significantly to predicting student performance on course exams. This current study, however, found positive correlations between facilitator evaluations and student performance on the PANCE. This is especially true for facilitator evaluations of students' knowledge integration, clinical reasoning, and self-directed learning. It is interesting that these are the key aspects of a PBL course and that they positively correlate with PANCE scores. Although facilitator evaluations positively correlate with the PANCE, they do not contribute significantly to the predictive validity of the PANCE above contributions made by MCQ and PMA scores. Yet, it is relevant that evaluations of students by a facilitator who is in a PBL group with those students for just six weeks positively correlate with student PANCE scores, and this holds true with multiple facilitators evaluating the same student. Many PA programs use some form of andragogy, including PBL. Particularly in programs that 
do not use MEQ exams such as the PMA, or which use MCQ exams with low variance in scores (where the majority of the class scores above 75, passing for most programs), use of an evaluation such as FER could contribute to prediction of students who may have difficulty passing the boards. This would allow for early remediation efforts, particularly using content related facilitator ratings (CR, KI, $\mathrm{SDL})$.

\section{Recommendations for Future Research}

An area for future research might include investigating other specific student behaviors that might impact success as defined by PANCE scores. As one example, a recent study revealed that number of practice tests students completed predicted actual PANCE scores. ${ }^{13}$ Future research needs to replicate this study and extend it by determining if scores on practice tests also predict actual PANCE scores. Other areas for future research might include determining if using data from the first year to identify students who are at-risk for poor performance and evaluate what kinds of remediation efforts can best assist these students and increase their likelihood of success.

In addition, future research needs to focus on impact of clinical rotations on PANCE scores. Such information can have both academic and clinical implications. For instance, a recent study discovered that PANCE score pass rates differ depending upon various dimensions of the supervised clinical practice experiences (SCPE's). One of those dimensions was whether or not there was a minimum score on preceptor evaluations needed. ${ }^{14}$ Another study found that end of rotation examinations have the ability to predict PANCE scores independent of PA program or version of the exams. ${ }^{15}$ Future work needs to evaluate usefulness of clinical preceptor assessments on prediction of PANCE scores. If there is correlation with some or all of the components of preceptor evaluations with PANCE scores, then students who receive low preceptor evaluations early in the clinical portion of the curriculum could receive strategies for correcting deficits, particularly if the behavioral areas (PAR, TS, EVAL, and COM) correlate with PANCE scores. Another area for future study would be correlation of these measures with employer evaluations after graduation from a PA program.

\section{Limitations}

One of the limitations of the current study include that all the students came from one program. This limits generalizability of these results to other institutions. Future research could include collaborations among multiple institutions to replicate and extend findings from this current study. Although the current study did utilize 140 students from several years of classes, increasing the number of participants and including students from multiple institutions will increase the generalizability of the findings and increase confidence in their applicability to other institutions. Another limitation of this study was that there is no previously established psychometric data for the faculty evaluation rating form. It will be critical for future researchers to establish the psychometric properties of such a form, especially given that rating of students on the attributes measured by the form used in this study is a key component of student assessment associated with the Southern Illinois University model of PBL.

\section{CONCLUSION}

This study suggests that it is possible to predict PANCE outcomes early in the first (didactic) year from evaluative measures in a program that uses PBL. One of the PMA examinations contributed to the predictive ability on the PANCE above two MCQ examinations alone. This study also suggests that facilitator evaluations, while not contributing to variance above MCQ and PMA examinations, do predict PANCE outcomes, which may encourage programs using PBL to collect and use facilitator evaluations to help guide remediation goals for students who are at risk of poor PANCE performance.

\section{References:}

1. Davenport J. Is there any way out of the androgogy morass? In: Thorpe M, Edwards R, Hanson A, editors. Culture and processes of adult learning. New York: Routledge; 1993. p. 109-117.

https://books.google.com/books?hl=en\&lr=\&id=2i5dAgAAQBAJ\&oi=fnd\&pg=PA109\&dq=definition+of+andragogy+in+education \&ots=JhRDTxB7VV\&sig=pYD8nDuPfgkRIOHy9SOqDf1IQA\#v=onepage\&q=definition\%20of\%20andragogy\%20in\%20education\&f=false. Accessed on March 8, 2019.

2. Barrows HS. Practice-based Learning: Problem-based Learning Applied to Medical Education. Springfield, IL: Southern Illinois University School of Medicine; 1994

3. Bate E, Hommes, J, Duvivier R, Taylor DCM. Problem-based learning (PBL): Getting the most out of your students -Their roles and responsibilities: AMEE Guide No. 84. Med Teach. 2014;36:1-12. [PMID: 24295273]

4. Wardley CS, Applegate EB, Van Rhee JA. A comparison of student knowledge acquisition by organ system and skills in parallel problem-based and lecture-based curricula. J Physician Assist Educ. 2013;24(1):5-14. [PMID: 23858821]

5. Jimenez-Saiz R, Rosace D. Is hybrid-PBL advancing teaching in biomedicine? A systematic review. BMC Med Ed. 2019;19:226. [ PMID: 31234856] 
6. Ennulat CW, Garrubba C, DeLong D. Evaluation of multiple variables predicting the likelihood of passage and failure of PANCE. J Physician Assist Educ. 2011;22(1):7-18. [ PMID: 21639072]

7. Massey SL, Lee L, Young S, Holmerud D. The relationship between formative and summative examination and PANCE results: A multi-program study. J Physician Assist Educ. 2013;24(1):24-34. [ PMID: 23858823]

8. Hegmann T, Roscoe M, Statler M. Reliability and validity of PAEA end of rotation ${ }^{\mathrm{TM}}$ examination scores for predicting performance on the physician assistant national certification examination. J Physician Assist Educ. 2015;26(4):187-192. [PMID: 26599311]

9. Whitfield CF, Xie SX. Correlation of problem-based learning facilitators' scores with student performance on written exams. Adv Health Sci Educ. 2002;7: 41-51. [PMID: 11912333]

10. Romito LM, Eckert GJ. Relationship of biomedical science content acquisition performance to students' level of PBL group interaction: Are students learning during PBL group? J Dent Educ. 2011;75(5):653-664. [PMID: 21546599]

11. Brown G, Imel B, Nelson A, Hale LS, Jansen N. Correlations between PANCE performance, physician assistant program grade point average, and selection criteria. J Physician Assist Educ. 2013;24(1):42-44. [ PMID: 23858825]

12. Butina $M$, Wyant $A R$, Remer $R$, Cardom R. Early predictors of students at risk of poor PANCE performance. J Physician Assist Educ. 2017;28(1):45-48. [PMID: 28125564]

13. Mirly AK, Domenech Rodríguez MM, Coombs JM. Board review course as intervention: Impact on PANCE performance. $J$ Physician Assist Educ. 2017;28(2):80-85. [PMID: 28471932]

14. Morici B, Bradford PD, Leese J. Investigational overview of supervised clinical practice experiences. J Physician Assist Educ. 2017;28(3):127-131. [PMID: 28762989]

15. Gietzen L, Roman C, Hegmann T. Reliability and validity of national end of rotation examinations: An Update. J Physician Assist Educ. 2018;29(2):86-8. [PMID: 29727430] 
APPENDIX

\begin{tabular}{|c|c|c|c|}
\hline Evaluated by: & Facilitator: & & Date: \\
\hline & $\begin{array}{c}\text { Exceeds } \\
\text { Expectations }\end{array}$ & High Satisfactory & Low Satisfactory \\
\hline $\begin{array}{l}\text { Clinical Reasoning: Asks for appropriate information to } \\
\text { develop diagnosis and treatment. Refines ideas list while } \\
\text { progressing through the case. }\end{array}$ & $\begin{array}{c}\square \\
90 \%-100 \% \text { of time }\end{array}$ & $\begin{array}{c}\square \\
70 \%-89 \% \text { of time }\end{array}$ & $\begin{array}{c}\square \\
50 \%-69 \% \text { of time }\end{array}$ \\
\hline \multicolumn{4}{|l|}{ Comments: Click here to enter text } \\
\hline $\begin{array}{l}\text { Knowledge Integration: Applies learning issues to problem } \\
\text { solution. Demonstrates ability to synthesize basic sciences and } \\
\text { physical diagnosis concepts and apply them to the case. Can } \\
\text { verbalize these processes to the group and answer questions } \\
\text { about them. }\end{array}$ & $\begin{array}{c}\square \\
90 \%-100 \% \text { of time }\end{array}$ & $\begin{array}{c}\square \\
70 \%-89 \% \text { of time }\end{array}$ & $\begin{array}{c}\square \\
50 \%-69 \% \text { of time }\end{array}$ \\
\hline \multicolumn{4}{|l|}{ Comments: Click here to enter text } \\
\hline $\begin{array}{l}\text { Self-Directed Learning: Comes to group thoroughly prepared } \\
\text { to share learning issues. Uses current, varied and appropriate } \\
\text { resources, including primary resources. }\end{array}$ & $\begin{array}{c}\square \\
90 \%-100 \% \text { of time }\end{array}$ & $\begin{array}{c}\square \\
70 \%-89 \% \text { of time }\end{array}$ & $\begin{array}{c}\square \\
50 \%-69 \% \text { of time }\end{array}$ \\
\hline \multicolumn{4}{|l|}{ Comments: Click here to enter text } \\
\hline $\begin{array}{l}\text { Participation: } \\
\mathrm{E}=\text { Freely shares thought processes and ideas; needs no } \\
\text { prompting, but not domineering of group. Helps others } \\
\text { participate. } \\
\text { HS = Usually shares, occasionally quiet or over-talkative. } \\
\mathrm{LS}=\text { Shares with some prompting from others, frequently over- } \\
\text { talkative. } \\
\mathrm{N}=\text { Typically talks over others/dominates conversations or rarely } \\
\text { talks in PBL without prompting. }\end{array}$ & $\begin{array}{c}\square \\
90 \%-100 \% \text { of time }\end{array}$ & $\begin{array}{c}\square \\
70 \%-89 \% \text { of time }\end{array}$ & $\begin{array}{c}\square \\
50 \%-69 \% \text { of time }\end{array}$ \\
\hline \multicolumn{4}{|l|}{ Comments: Click here to enter text } \\
\hline $\begin{array}{l}\text { Team Skills: Exhibits concern/demonstrates sensitivity to level } \\
\text { of understanding of all group members; helps to explain difficult } \\
\text { concepts to group members to further their understanding. On } \\
\text { time to group meetings and PBL: } \\
E=\text { never late } \\
H S=\text { no more than } 1 \text { times late } \\
L S=\text { no more than } 3 \text { times late } \\
N=\text { late more than } 3 \text { times }\end{array}$ & $\begin{array}{c}\square \\
90 \%-100 \% \text { of time }\end{array}$ & $\begin{array}{c}\square \\
70 \%-89 \% \text { of time }\end{array}$ & $\begin{array}{c}\square \\
50 \%-69 \% \text { of time }\end{array}$ \\
\hline \multicolumn{4}{|l|}{ Comments: Click here to enter text } \\
\hline $\begin{array}{l}\text { Evaluation Process: Gives constructive feedback to others; is } \\
\text { capable of accurate positive and constructive self-assessment. } \\
\text { Can listen to constructive criticism without arguing or defending. }\end{array}$ & $\begin{array}{c}\square \\
90 \%-100 \% \text { of time }\end{array}$ & $\begin{array}{c}\square \\
70 \%-89 \% \text { of time }\end{array}$ & $\begin{array}{c}\square \\
50 \%-69 \% \text { of time }\end{array}$ \\
\hline \multicolumn{4}{|l|}{ Comments: Click here to enter text } \\
\hline $\begin{array}{l}\text { Communication Skills: Communicates clearly, concisely, and } \\
\text { respectfully to all group members and facilitator; demonstrates } \\
\text { the ability to speak to the level of a patient and/or to speak to } \\
\text { the level of a preceptor. Uses appropriate non-verbal } \\
\text { comportment. Uses appropriate medical terminology. }\end{array}$ & $\begin{array}{c}\square \\
90 \%-100 \% \text { of time }\end{array}$ & $\begin{array}{c}\square \\
70 \%-89 \% \text { of time }\end{array}$ & $\begin{array}{c}\square \\
50 \%-69 \% \text { of time }\end{array}$ \\
\hline
\end{tabular}

Figure 1. Facilitator Evaluation Form 